\section{Estudo \\ CoDebate}

em Testão

Planejamento
Revista Estudo \& Debate, Lajeado, v. 25, n. 1, 2018. ISSN 1983-036X

DOI: http://dx.doi.org/10.22410/issn.1983-036X.v25i1a2018.1408

\title{
O SETOR SUCROALCOOLEIRO E O VALOR DA TERRA AGRÍCOLA EM GOIÁS E EM MINAS GERAIS: UMA ANÁLISE ECONOMÉTRICA
}

\author{
Antonio Marcos de Queiroz ${ }^{1}$, Juliene Barbosa Ferreira ${ }^{2}$, Josiane Souza de Paula ${ }^{3}$
}

\begin{abstract}
Resumo: Este artigo tem como objetivo analisar se existe alguma influência do setor sucroalcooleiro nos estados de Goiás e Minas Gerais na dinâmica do valor da terra agrícola, principalmente nas áreas de alta produtividade. Foi utilizada a metodologia baseada no modelo de dados em painel nos anos de 2003 a 2012 extraídos do Agrianual e do IBGE. Os resultados apontam que as variáveis: valor da produçáo, produtividade da soja, do milho e da cana-de-açúcar e presença das usinas apresentaram uma correlaçấo positiva com o valor da terra por meio do acréscimo da renda auferida. Há portanto, influência da política de estímulo à produçáo de etanol no Brasil que expandiu o setor produtor de cana-de-açúcar nesses estados, levando a uma alteraçáo do valor da terra agrícola. Conclui-se que o valor da terra em Minas e Goiás tem forte relaçáo com a renda obtida deste fator e que a elevaçáo da produtividade levaria a um acréscimo na renda da terra, o que a torna mais atrativa, elevando a sua demanda e assim valorizando-a.
\end{abstract}

Palavras-chave: Valor da Terra. Setor Sucroalcooleiro. Goiás. Minas Gerais. Dados em Painel.

\section{THE SUGARCANE SECTOR AND THE VALUE OF AGRICULTURAL LAND IN GOIÁS AND MINAS GERAIS: AN ECONOMETRIC ANALYSIS}

\begin{abstract}
This paper aims to analyze whether there is some influence in the sugar ethanol sector in the States of Goiás and Minas Gerais in the dynamics of the value of agricultural land, mainly in the areas of high productivity. The methodology was based on panel data model in the years 2003 to 2012 extracted from Agrianual and IBGE. The results show that the variables: production value, productivity of soybean, corn and sugar cane, and the presence of the plants showed a positive correlation with the value of the Earth through the addition of income earned. There is therefore, influence of policy stimulus to production of ethanol in Brazil that expanded the industry the sugar-cane producer in those States, leading to a change in the value of
\end{abstract}

1 Professor Adjunto de Economia na FACE/UFG. Universidade Federal de Goiás. Doutor em Economia pela Universidade Federal de Uberlândia - IE/UFU. E-mail: antonio.mq10@gmail.com

2 Professora Assistente na FACIP/UFU. Universidade Federal de Uberlândia. Doutora em Economia pela Universidade Federal de Uberlândia - IE/UFU. E-mail: juliene@pontal.ufu.br

3 Doutora em Economia pela Universidade Federal de Uberlândia - IE/UFU. E-mail: Josiane_udi@yahoo.com.br 
agricultural land. It is concluded that the value of land in Minas Gerais and Goiás has a strong relationship with the proceeds of this factor and higher productivity would lead to an increase in the rent of land, which makes it more attractive by raising your demand and thus valuing it.

Keywords: Land Value. Sugarcane Sector. Goiás. Minas Gerais. Panel Data.

\section{INTRODUÇÃO}

A discussão sobre o valor da terra está presente na literatura econômica desde a economia clássica. Os fisiocratas consideravam a terra como a principal atividade de produção de uma economia agrária. Malthus (1996), Ricardo (1988) e Marx (2008) estão entre os primeiros autores que relacionaram o valor da terra a sua capacidade de geraçáo de renda. Já na economia neoclássica, a terra é considerada do ponto de vista da produtividade marginal enquanto fator de produção ou também pela geração de renda futura por meio da capitalizaçáo da taxa de juros.

No Brasil, vários estudos empíricos foram realizados para a determinação do valor da terra tanto de uma dimensão produtiva como de uma visão especulativa (PINHEIRO, 1980; SAYAD, 1977; RANGEL, 1979; REYDON, 1984; BRANDÁO, 1986; BRANDÃO, REZENDE, 1992; BACHA, 1989; ROMEIRO, REYDON, 1994; REYDON, PLATA, 1995; BARROS, 2009; FERRO, CASTRO, 2013).

Nas décadas de 1970 e 1980, os debates sobre os principais determinantes da formaçáo do valor da terra agrícola foram direcionados segundo a ótica da decisão do produtor pela expansão da atividade, observando a demanda por terra, quanto a rentabilidade futura do negócio, seja pelos valores pagos ou pelos valores recebidos no mercado, como defendeu Sayad (1977) e Pinheiro (1980). Segundo Sayad (1977), a demanda por terra (enquanto reserva de valor) é maior em períodos de inflação, competindo com o mercado financeiro. Já Rangel (1979) concluiu que a oferta de terra ocorre em função das inovaçóes tecnológicas, que elevam a sua produtividade, a qual é determinante do valor da terra.

Ao longo dos anos novas variáveis foram adicionadas ao debate da formaçáo do valor da terra agrícola. Castro (1981), por exemplo, destacou o papel das políticas públicas na criação de mecanismos de incentivos e creditícios. Segundo ele, estes fatores foram importantes para alteração da infraestrutura, da localização e do acesso às terras de maior valor. Entretanto, é importante enfatizar o processo de concentraçáo da posse da terra e, consequentemente, a exclusáo da pequena propriedade do processo tecnológico, caso dos programas governamentais de desenvolvimento na regiáo dos cerrados.

Nos anos 90, com a estabilidade econômica proveniente do Plano Real, a demanda por terra se reduziu devido à elevação das taxas de juros e pelo controle da inflação. O resultado foi o direcionamento do investimento para o mercado financeiro, em busca de ativos mais rentáveis. Além disso, tal efeito reduziu o valor da terra, uma vez que a especulação por este ativo diminuiu, porém as altas taxas de juros prejudicaram os produtores nacionais que se endividaram, ao mesmo tempo em que ficaram expostos a concorrência do mercado externo com o processo de abertura comercial (DELGADO; FERNANDES FILHO, 1998).

Deste modo, nas décadas de 70, 80 e 90, concomitantemente a este processo de variação do valor da terra na agricultura, o crédito agrícola somado as inovaçóes tecnológicas 
influenciaram o processo de expansão da fronteira agrícola, permitindo a correção dos solos e a agregação de valor de terras de menor produtividade agrícola e, consequentemente, rentabilidade e renda fundiária mais elevadas que foram auferidas pelo produtor (DELGADO; FERNANDES FILHO, 1998).

Nos anos 2000, com as projeções de crescimento da demanda mundial por energia e alimentos, houve novamente uma pressão sobre o valor da terra, sobretudo nas áreas de alta produtividade. $\mathrm{O}$ resultado foi o aumento dos valores das commodities agrícolas, como soja, milho e carnes e, também do etanol (devido a política de expansão do setor sucroalcooleiro no Brasil). Deste modo, acredita-se que o valor da terra seja influenciado por variáveis como o crédito rural, a elevação dos valores das commodities, a elevação da demanda por etanol, a expansão do cultivo de cana-de-açúcar para além do estado de São Paulo, como Goiás, Mato Grosso do Sul, Minas Gerais e Paraná (LIMA, 2010).

Nesse sentido, o objetivo deste estudo é analisar se existe alguma influência do setor sucroalcooleiro nos estados de Goiás e Minas Gerais na dinâmica do valor da terra agrícola, principalmente nas áreas de alta produtividade, no período entre 2003 a 2012. O estudo se justifica pela carência de análises sobre o valor da terra agrícola, principalmente nestes estados, Goiás e Minas Gerais. O processo inflacionário antes da década de 90 impulsionava a maior demanda por terra que alterou a lógica do seu uso, passando da especulação para a produção. O referencial teórico vai mostrar este processo de transformação do uso da terra no Brasil. Já a análise empírica, com a expansão do setor sucroalcooleiro nestes estados, revela que a renda da terra é importante, na medida em que outras culturas tradicionais (soja e milho) vão disputar o espaço com a cana-de-açúcar, influenciando o valor da terra. Além desta introdução, este estudo está dividido em cinco seçóes: a segunda seção apresenta a revisão da literatura acerca dos fatores que influenciam o valor da terra no Brasil e a expansão do setor sucroalcooleiro; na terceira seção é apresentada a metodologia do trabalho e as fontes de dados utilizados; a quarta seção remete a discussão dos resultados obtidos; e, por fim, na quinta é apresentada as consideraçóes finais.

\section{REFERENCIAL TEÓRICO}

\subsection{O valor da terra no Brasil}

Historicamente, desde os fisiocratas no Século XVIII, a terra é considerada como o principal meio de produção de uma economia agrária. No século XIX, as influências da Lei do Trigo e as conclusóes de Malthus (1996), resultou na ocupação dos estudos de Ricardo (1988) e Marx (2008). Os estudos iniciais sobre o tema originam de teorias que vinculam o valor da terra à sua capacidade de geração de renda, resultando na chamada "teoria da renda diferencial", que foi formalizada de modo mais completo por David Ricardo (1988) (PINHEIRO, 1980; FERREIRA; MIZIARA; RIBEIRO, 2007).

Usualmente a literatura adota pressupostos que relaciona o valor da terra à renda que ela pode originar. $\mathrm{Na}$ corrente neoclássica, o valor da terra é determinado pela produtividade marginal do fator, enquanto que os autores marxistas consideram a renda futura da terra por meio da capitalização do nível da taxa de juros da economia (REYDON, 1992). 
Segundo Egler (1985) e Plata (2006), no Brasil, os estudos empíricos dos fatores que determinam o valor da terra na agricultura têm sido preocupação de vários autores (PINHEIRO, 1980; SAYAD, 1977; RANGEL, 1981; REYDON, 1984; BRANDÃO, 1986; BRANDÃO, REZENDE, 1992; BACHA, 1989; ROMEIRO; REYDON, 1994; REYDON, PLATA, 1995; BARROS, 2009; FERRO, CASTRO, 2013; MALASSISE et al., 2015). Esses trabalhos também ressaltam os atributos produtivos e especulativos da terra agrícola. O debate tem assumido relativa importância, haja vista que os valores da terra na agricultura se tornaram referências para a tomada de decisão dos agentes sobre este ativo quanto: a aquisição e venda; a parametrização na determinação de hipoteca pelas instituiçóes financeiras; a referências para os programas sociais, econômicos, fiscais e ambientais governamentais.

Conforme Sayad (1977) e Pinheiro (1980), os principais determinantes da formação do valor das terras agrícolas são influenciados pela decisão do agricultor em expandir a atividade pela demanda por terra relacionada com a produção. Isso significa que a decisão de investir na atividade agrícola depende da rentabilidade da agricultura, utilizando os mecanismos de troca com o índice mais adequado seria a relação entre os preços recebidos e pagos pelos agricultores.

Na visão de Rangel (1979), o valor da terra é determinado pela sua própria oferta, em função do progresso técnico, com elevação da produtividade na agricultura e na construção civil, exceto em momentos de reversão cíclica, com a demanda de especulação por terras. Contudo, segundo o autor, o empirismo não valida a hipótese de que os valores da terra são determinados especialmente pela rentabilidade do setor agrícola.

Plata (2001) corrobora com a visão de Rangel (1979) e afirma que valor da terra é determinado pelas expectativas de rendas produtivas e especulativas oriundas da propriedade, influenciadas pelo dinamismo entre a oferta e demanda; pelas rendas originadas da utilização produtiva da terra; pela infraestrutura de produção e comercialização; pela alta fragmentação da vegetação nativa; pelas variáveis demográficas; pela inflação; pelos impostos e tributos; pelos custos de transação e pelo ambiente socioeconômico e político em que as transaçóes com as terras ocorrem.

Existem outros estudos empíricos importantes no mercado de terras, para as instituiçóes financeiras, programas sociais, fiscais e ambientais do governo para o período de 1960 e 2011 que foram levantadas por Malassise (2015), conforme o Quadro 1 abaixo.

Quadro 1. Evolução dos estudos empíricos sobre o preço da terra no Brasil

\begin{tabular}{|c|c|c|c|c|}
\hline Estudo & Período & Abrangência & Variáveis Explicativas & Conclusóes \\
\hline $\begin{array}{c}\text { Oliveira e } \\
\text { Costa (1976) }\end{array}$ & $1966-1974$ & 16 Estados do Brasil & $\begin{array}{c}\text { Preço recebido, preço pago, } \\
\text { densidade viária, índice } \\
\text { tecnológico e área agricultável } \\
\text { total }\end{array}$ & $\begin{array}{c}\text { As variáveis significativas foram: } \\
\text { preço recebido, densidade viária } \\
\text { e índice tecnológico. }\end{array}$ \\
\hline $\begin{array}{c}\text { Pinheiro } \\
(1980)\end{array}$ & $1966-1978$ & 16 Estados do Brasil & $\begin{array}{c}\text { Relação preço da terra, a renda } \\
\text { da terra e a inflaçáo }\end{array}$ & $\begin{array}{c}\text { As evidências empíricas } \\
\text { demonstraram que tanto a } \\
\text { renda quanto a inflaçáo sáo } \\
\text { significativas. }\end{array}$ \\
\hline
\end{tabular}




\begin{tabular}{|c|c|c|c|c|}
\hline $\begin{array}{l}\text { Reydon } \\
(1984)\end{array}$ & $1970-1975$ & 17 Estados do Brasil & $\begin{array}{l}\text { Crédito Rural e fator de } \\
\text { rentabilidade por homem } \\
\text { ocupado }\end{array}$ & $\begin{array}{l}\text { O crédito e o nível de } \\
\text { tecnificaçáo representado pela } \\
\text { rentabilidade por homem } \\
\text { ocupado foram significativas }\end{array}$ \\
\hline $\begin{array}{l}\text { Brandão } \\
(1986)\end{array}$ & $1966-1984$ & Brasil & $\begin{array}{c}\text { Crédito agrícola, preço recebido, } \\
\text { hiato produto (proxy de eido } \\
\text { econômico) }\end{array}$ & $\begin{array}{l}\text { Crédito significativo para terras } \\
\text { de lavoura, preço recebido } \\
\text { significante para pecuária, hiato } \\
\text { produto significativo para o todo. }\end{array}$ \\
\hline $\begin{array}{l}\text { Brandão } \\
(1988)\end{array}$ & $1966-1981$ & $\begin{array}{l}\text { Região Centro-Sul } \\
\text { do Brasil }\end{array}$ & $\begin{array}{l}\text { Crédito rural, hiato produto } \\
\text { (proxy para ciclos) e relaçáo preço } \\
\text { recebido/preço pago (proxy para } \\
\text { rentabilidade) }\end{array}$ & $\begin{array}{l}\text { Crédito rural significativo, com } \\
\text { maior elasticidade de preço para } \\
\text { terra de lavoura que pastagem. } \\
\text { Ciclo e rentabilidade não } \\
\text { significativos. }\end{array}$ \\
\hline $\begin{array}{l}\text { Brandão } \\
\text { e Resende } \\
(1959) \\
\end{array}$ & $1966-1986$ & $\begin{array}{l}\text { Regido Centro-Sul } \\
\text { do Brasil }\end{array}$ & $\begin{array}{l}\text { Preços recebidos, produtividade, } \\
\text { subsidio ao crédito }\end{array}$ & Significantes e positivas \\
\hline Bacha (1989) & $1970-1985$ & Minas Gerais & $\begin{array}{l}\text { Preço recebido/preço pago } \\
\text { pelo agricultor, taxa de juros } \\
\text { do crédito rural; taxa de juros } \\
\text { financeira; nível tecnológico, } \\
\text { preço real dos insumos, dummy } \\
\text { para ITR, inflaçáo e taxa de } \\
\text { crescimento do PIB }\end{array}$ & $\begin{array}{c}\text { As estimativas preliminares } \\
\text { confirmaram os sinais esperados } \\
\text { dos parâmetros }\end{array}$ \\
\hline Plata (2001) & 1966-1999 & Brasil & $\begin{array}{c}\text { Renda da terra, inflação e } \\
\text { dummies para modernização } \\
\text { agrícola, Planos de estabilização } \\
\text { Cruzado e Real }\end{array}$ & $\begin{array}{c}\text { Todas as variáveis foram } \\
\text { significativas e positivas. Destaca- } \\
\text { se apenas que a dummy para } \\
\text { inflação teve comportamento } \\
\text { diferenciado }\end{array}$ \\
\hline $\begin{array}{l}\text { Dias, Vieira } \\
\text { e Amaral } \\
(2001)\end{array}$ & $\begin{array}{l}\text { Década de } \\
\quad 90\end{array}$ & Brasil & $\begin{array}{l}\text { Crédito rural, preço recebido, } \\
\text { preço pago, hiato produto, } \\
\text { inflaçáo e produtividade }\end{array}$ & $\begin{array}{l}\text { Com exceção do crédito rural } \\
\text { que foi positivo mas não } \\
\text { significativo, todas as variáveis } \\
\text { foram positivas e significativas. }\end{array}$ \\
\hline $\begin{array}{l}\text { Michellon } \\
\text { (2002) }\end{array}$ & $\begin{array}{l}1970-1998 \\
1989-1996\end{array}$ & Paraná & $\begin{array}{c}\text { Ambiental - controle de erosáo } \\
\text { tem impacto no mercado de } \\
\text { terras }\end{array}$ & $\begin{array}{l}\text { Positivo para o controle da } \\
\text { erosáo. }\end{array}$ \\
\hline $\begin{array}{l}\text { Gasques et at. } \\
\qquad(2006)\end{array}$ & $1977-2004$ & Brasil & $\begin{array}{l}\text { Crédito rural, produtividade } \\
\text { total dos fatores }\end{array}$ & $\begin{array}{c}\text { Crédito rural foi positivo } \\
\text { e significativo, tendo mais } \\
\text { importância que a produtividade } \\
\text { total dos fatores. }\end{array}$ \\
\hline $\begin{array}{l}\text { Plata et al. } \\
\text { (2011) }\end{array}$ & $2002-2010$ & Brasil & $\begin{array}{c}\text { Área destinada à reforma agrária } \\
\text { e preço da soja }\end{array}$ & $\begin{array}{c}\text { As variáveis foram significativas } \\
\text { e positivas. }\end{array}$ \\
\hline
\end{tabular}

Fonte: Malassise et al. (2015)

Náo há necessidade da queda do lucro da economia para o valor da terra elevar, já que em 1971 ocorreu a elevaçáo dos valores da terra em concomitante processo de crescimento da economia brasileira após o milagre brasileiro (1968-1974). Entretanto, no período de maior expansão da economia brasileira, elevou-se o processo de especulaçáo sobre as terras agrícolas (PINHEIRO; REYDON, 1981),

A presença das políticas públicas agrícolas, especialmente sobre os produtos voltados para o mercado doméstico, prejudica o mercado agrícola em desenvolver naturalmente, reduzindo a rentabilidade da agricultura em relação ao valor da terra. A resultante foi à gradativa procura por terras, uma vez que no período houve mobilizaçáo em terra, garantindo retornos comparados com outros ativos (CASTRO, 1981). 
Em conformidade, Sayad (1977) aponta que a rentabilidade da agricultura seria menos dependente da expectativa de valorização ativo enquanto patrimônio. Tal viés proporciona um nível menor de produção nos latifúndios, elevação dos processos de concentração da terra, prejudicando a produção na pequena propriedade, principalmente a condição de capitalização. A aquisição tecnológica, a valorização do ativo, por vários motivos, não estimula nem pequenos, nem grandes propriedades na elevação da produtividade, quanto à área cultivada.

Outra questão é a alternativa da aquisição terras em períodos de inflação. Castro (1981) questiona se a inflação seria responsável pela geração de valor da terra. Para ele, isso só seria possível após um período de intensa liquidez conjugada com os créditos agrícolas concedidos pelo governo. Não é a inflação, mas a disponibilidade real em ativos monetários que influenciará no valor da terra, como ocorreu no período de 1971-1973.

Em resumo, destaca-se que na década de 70 , entre os principais fatores determinantes do valor da terra estavam: a expectativa de aumento da taxa de lucro da produção, o grau de liquidez real da economia nos períodos de prosperidade, o crédito rural, as obras de infraestrutura realizadas pelo governo, o programa nacional do álcool e os incentivos fiscais. Chama-se atenção para o crédito rural e a liquidez da economia, que levaram consequentemente, a demanda por ativos financeiros e não financeiros, majorando a demanda e o valor das terras (SAYAD, 1977; PINHEIRO; REYDON, 1981; CASTRO; FONSECA, 1994).

De acordo como Dias, Vieira e Amaral (2001) os estímulos do crédito rural subsidiado geraram um crescimento real do valor da terra por meio da capacidade de alavancagem que a terra propiciava quando os bancos a usavam como paralelo nos contratos financeiros para a aquisição de empréstimos subsidiados. Em contrapartida, o crédito proporcionava modernização e impulsionava a produtividade na agricultura e, por conseguinte, uma rentabilidade superior para os agricultores.

Ferro e Castro (2013) analisaram neste mesmo período a relação entre o valor da terra e o ciclo econômico. Os autores comprovaram a elevação do mesmo em um ritmo maior do que o valor do arrendamento, confirmando que as vantagens de posse da terra enquanto ativo supera aquelas oriundas da atividade intrinsecamente agrícola.

Além disso, a partir da década de 70 , ocorreu o processo de expansão da fronteira agrícola para o Centro-Oeste, graças à combinação de políticas públicas com os programas de desenvolvimento com a incorporação de novas tecnologias modernas. O cerrado passou a ser considerado um importante cenário de variação do valor da terra no Brasil (CASTRO; FONSECA, 1994).

O aspecto mais relevante neste modelo sugerido por Rezende (2002) é a capacidade de conversão das terras virgens e de segunda em terras de primeira, a partir da aplicação de tecnologias (inovaçóes tecnológicas de correção do solo, como a calagem e adubação), ou seja, "a produção de terras" com a elevação da produtividade. Assim, o autor critica os modelos tradicionais que partem do pressuposto da existência de uma quantidade limitada de terras em qualidade suficiente para serem incorporadas imediatamente ao processo 
produtivo, já que a tecnologia supera o problema da disponibilidade limitada de terras (FERREIRA; MIZIARA; RIBEIRO, 2007).

Entretanto, a adoção de novas tecnológicas para corrigir o solo com a utilização de calagem e adubaçáo na conversão de terras virgens e de segunda em terras de primeira náo tende a evitar a incorporação de novas áreas de terras no cerrado, principalmente em regióes de terras de maior produtividade agrícola.

A produtividade pode apresentar uma relação inversa com o valor da terra enquanto há condiçóes de aumentá-la, ou seja, enquanto os investimentos em inovaçóes tecnológicas (máquinas, adubos, fertilizantes, por exemplo) proporcionarem elevação da produtividade para obtençáo de maior renda por área cultivada. Entretanto, a partir do momento em que a produtividade atinge estabilidade no nível máximo, o aumento da produção dependeria da expansão da área de cultivo, resultando na valorização da terra (BARROS, 2009). De acordo com a teoria econômica convencional, a formação da renda fundiária agrícola é auferida pelas diferenças de preços unitários do solo agrícola, explicadas pela renda diferencial por duas causas: a fertilidade natural e a localização. $\mathrm{O}$ valor da terra tem sido influenciado pelos benefícios causados pela infraestrutura construída de estradas, canais de irrigação, redes de energia elétrica; pela disponibilidade natural de fontes e nascentes de água e também pela elevação do arrendamento (DIAS; VIEIRA; AMARAL, 2001; FERREIRA; MIZIARA; RIBEIRO, 2007).

Segundo esse modelo, o agente econômico "capitalista” busca sempre a maximização do lucro ao realizar investimentos. Portanto, o empresário agrícola quando deseja expandir sua produçáo faz cálculos racionais que lhe garanta o máximo retorno possível de seus investimentos e, consequentemente, a maximização do lucro.

Delgado e Fernandes Filho (1998) afirmam que em 1994, a implantação do Plano Real significou uma forte mudança da política econômica de combate à inflação, combinando uma política monetária de juros elevados e câmbio sobrevalorizado, o efeito foi devastador sobre a renda fundiária vis-à-vis com a deterioração dos valores médios da terra e a queda generalizada da renda agrícola com a abertura comercial. A reduçáo drástica da inflação colaborou para que a terra, enquanto ativo de especulação perdesse sua atratividade (enquanto reserva de valor) em relação aos demais ativos reais e financeiros, o que afetou de forma negativa as rendas futuras (DELGADO, FERNANDES FILHO, 1998; DELGADO, 2005).

Além disso, nesta mesma direção, a política de altas taxas de juros reduziu as expectativas de ganhos produtivos. O preço da terra caiu em relação ao resto da economia, mas não se alterou em relação ao valor do insumo para o produtor com alta tecnologia. Com a queda do valor da terra, o prejuízo atingiu tanto os grandes proprietários fundiários (principalmente aqueles com terras pouco produtivas e dívidas) quanto os produtores familiares (endividados pelas altas taxas de juros e correção monetária) (RAHAL, 2003).

Portanto, a variação do valor da terra pode ser explicada em vários períodos da história. Nos anos 60 ocorreram importantes mudanças na agricultura brasileira, como o choque tecnológico com o uso de modernos insumos (adubos, sementes melhoradas, calcário), a elevação da produtividade agrícola, a forte política de crédito rural subsidiado, 
a criação de programas desenvolvimentistas que permitiu a expansão da infraestrutura, cidades, rodovias, canais de distribuição da produção agrícola aos mercados consumidores e para exportação e, graças a expansão da fronteira agrícola. $\mathrm{Na}$ década de 70 , o valor da terra foi constituído por forças da demanda (dada à alta concentração da terra), com o monopólio dos grandes proprietários em fixar preços, com alta rentabilidade e valorização dos ativos. O valor da terra passa a ser determinado por variáveis microeconômicas, como os preços relativos, a produtividade, os incentivos de crédito e, macroeconômicas, como a inflação e o nível da atividade coma melhor infraestrutura e serviços públicos. Nos anos $80 \mathrm{e}$ 90, o valor da terra foi determinado pelas flutuaçóes econômicas, os preços relativos (pagos e recebidos pelos produtores), a produtividade agrícola, a taxa de juros e a instabilidade econômica medida pela inflação (DIAS; VIEIRA; AMARAL, 2001).

Para o período de 2000 a 2006, conforme Gasques, Bastos e Valdes (2008), a elevação do valor da terra no Brasil foi determinada por vários fatores: a taxa de câmbio favorável às exportaçóes agrícolas, permitindo que os complexos agroindustriais se aproveitassem desta situação, como os de soja e carnes e derivados; o crédito rural com a elevação de recursos para os produtores e cooperativas, como o Programa Moderfrota (tratores e máquinas agrícolas); a elevação dos preços internos e externos das commodities agrícolas, como soja, milho e carnes; entre outros. Nas regiôes de produção de cana-de-açúcar houve forte pressão pela elevação do valor da terra. No período até 2012, a elevação da demanda mundial por biocombustíveis, em substituição ao petróleo elevou os preços dos produtos agrícolas e, consequentemente, a pressão por maior utilização de lavouras de cana, soja e milho.

Entre as razóes que impulsionaram o crescimento da demanda internacional por biocombustíveis, destaca-se: i) crescente elevação do comércio de açúcar e álcool no mercado interno e externo; ii) crise e a valorização do preço do barril de petróleo no mercado internacional, dada sua escassez e a alta emissão de gases poluentes de CO2 na atmosfera; iii) aumento da demanda interna por álcool hidratado, devido ao aparecimento dos novos modelos de carros flexfuel; iv) o protocolo de Kyoto, que devido às alteraçóes climáticas e ao aquecimento global, defende a redução da emissão de gás carbônico, contribuindo para a elevação da demanda internacional por álcool anidro de outros países da Europa, Ásia e América (UNICA, 2011).

Nesta perspectiva, a partir do ano de 2003 houve uma expressiva demanda por terras agrícolas destinadas à produção de biocombustíveis. Assim, o governo passou a estimular a implantação e expansão de usinas produtoras de etanol, em São Paulo, estado tradicionalmente produtor de cana para os estados de Minas Gerais (principalmente Triângulo Mineiro e Alto Paranaíba) e Goiás (principalmente, Sul e Sudoeste Goiano). Estas regióes embora apresentassem pouca tradição no cultivo da cana, eram altamente produtoras de grãos e de alta produtividade agrícola.

Segundo Silva e Miziara (2011), o Plano Nacional de Agroenergia 2006-2011 lançado pelo Ministério da Agricultura, Pecuária e Abastecimento (MAPA) no ano de 2006, tem como objetivo expandir a agricultura para a produção de energia com a agregação de cadeias agroindustriais. A finalidade era priorizar um processo de interiorização e regionalização do desenvolvimento e privilegiar regióes menos desenvolvidas, como por exemplo, as áreas de pastagens degradadas, sem comprometer a vegetação nativa ou a produçáo de alimentos 
(soja e o milho). Entretanto, isso levou a expansão da cultura canavieira e das agroindústrias nos estados de Goiás e Minas Gerais, para terras férteis de alta produtividade agrícola, produtoras de soja e milho. $\mathrm{O}$ resultado deste processo conflituoso do uso do solo tem majorado crescentemente o valor da terra nestas regióes.

\subsection{Panorama da produçáo de cana-de-açúcar}

A CONAB (2014) ainda analisa que a expansão da área cultivada tem comportamento diferenciado na extensão brasileira. Destaque para o percentual de aumento constatado na Região Sudeste, com 96,38\% do total da nova área, representando 357.183 hectares, concentrados principalmente em São Paulo, com aumento de 246.011 hectares e Minas Gerais 106.640 hectares. O Centro-Oeste também teve significativa representatividade na expansão, aumentando em 188.396 hectares a área de plantio, compreendida por 115.792 hectares de Goiás e, 65.347 hectares por Mato Grosso do Sul. Em consequência de tal aumento em área de cultivo, podemos observar na Figura 1 que o volume de cana-de-açúcar moída, segue paralelamente, ampliando a produtividade no país.

Figura 1 - Evolução da área plantada e produtividade da cana-de-açúcar no Brasil

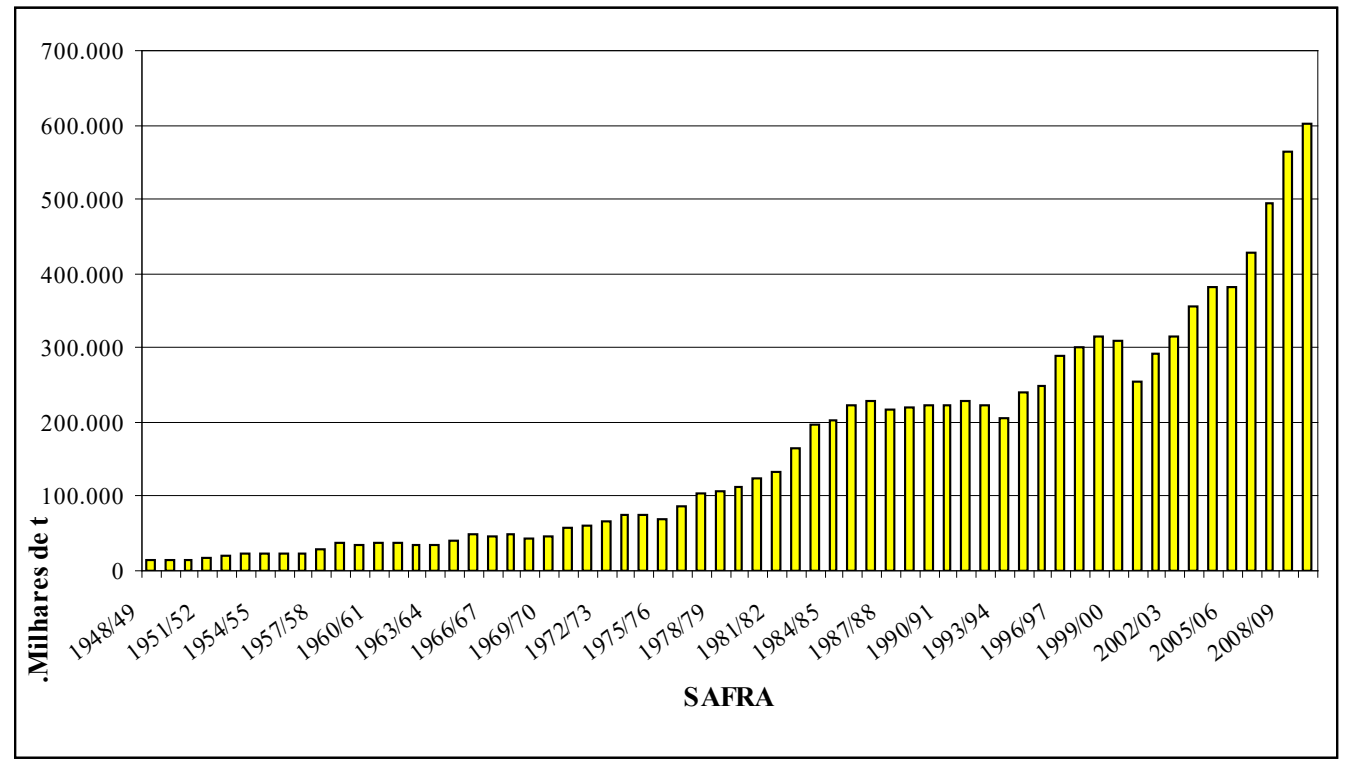

Fonte: Elaboração própria com dados do Ministério da Agricultura, Pecuária e Abastecimento (BRASIL, 2013).

Goiás foi um dos estados que mais obteve destaque no recente ciclo da expansão da cana-de-açúcar no Brasil. O aumento percentual acumulado da produção de cana entre as safras 2000/01 a 2011/12 foi de 527\%, passando à frente dos Estados de Alagoas, Mato Grosso do Sul, Paraná e Pernambuco (UNICA, 2013).

Dentre municípios goianos que são destaque no setor sucroalcooleiro estão: Goiatuba, Itumbiara, Porteirão, Goianésia, Quirinópolis, Turvelândia, Edéia, entre outros. O estado de Goiás apresenta significativa extensấo de áreas aptas ao cultivo da cana-de-açúcar e a 
também extensão de áreas aptas ainda não cultivadas com cana, ou seja, pode-se dizer que sob o aspecto de disponibilidade de terras, o estado se apresenta com o maior potencial de crescimento do setor no país (OTTO; NEVES; PINTO, 2012).

Segundo a FAEG (2009), de forma pontual, dentro da crescente expansão da canade-açúcar no país, o estado de Goiás apresentou uma importante participação em duas etapas. A primeira, foi a partir dos anos 80 , influenciado pelo primeiro ciclo do Proálcool e; a segunda, a partir de 2003, ano que se iniciou um grande avanço de novas usinas e a política de expansáo das usinas existentes. Neste segundo momento destaca-se uma política de incentivos fiscais e financiamentos do Banco Nacional de Desenvolvimento Econômico Social (BNDES) e recursos do Fundo Constitucional do Centro-Oeste (FCO), na consolidação da meta do governo estadual que pretendia consolidar o estado como o novo celeiro da produção de etanol no Brasil (FAEG, 2009).

Para Otto, Neves e Pinto (2012) é notória a prioridade do investimento e do incentivo fiscal por parte do governo goiano, por meio do Programa Produzir, passou a fomentar e subsidiar o crescimento do setor sucroalcooleiro no estado. No período de 2003 a 2010, os investimentos no setor alcançaram $R \$ 5.959 .798 .112$, o que corresponderam a $62,2 \%$ do total dos investimentos destinados a implantação e expansão de vários segmentos no período. Já os incentivos para o setor foram da ordem de $\mathrm{R} \$ 23.423 .607 .478$, correspondendo a $37,5 \%$ do total dos incentivos destinados a todos os segmentos fomentados no período (OTTO; NEVES; PINTO, 2012).

Portanto, a atraçáo de investimentos para o cultivo da cana-de-açúcar e a produção de etanol e açúcar seria reforçada pela logística do estado, pelas terras de maior produtividade, de extensas áreas planas, de menor custo de aquisição (comparadas com as terras de São Paulo), como também pelas alternativas de escoamento da produção (FAEG, 2009). A combinação destas variáveis tem impactos diretos na valorização das terras agrícolas, embalada pela expansão do setor sucroalcooleiro no estado, com o maior cultivo da canade-açúcar.

No que se refere ao Estado de Minas Gerais, de acordo com Guimarães (2011), o estado já possui $0,5 \%$ do território de cana-de-açúcar no Brasil, sendo $70 \%$ na região do Triângulo Mineiro, que sofreu um aumento de $129,44 \%$ na área de plantio. Conforme o Sindicato da Indústria do Açúcar e do Álcool de Minas Gerais - Siamig/Sindaçúcar (CANA BRASIL, 2009), no ano de 2010 eram dezesseis usinas em funcionamento, com previsão que outras seis entrassem em operação até o fim do mesmo ano.

A região do Triângulo Mineiro tem atraído investidores devido às medidas de programas do Governo Federal (Programa de Aceleraçáo do Crescimento - PAC) que abrangem açóes estaduais e empreendimentos de abrangência regional, no que tange aos eixos de infraestrutura logística, energética, social e urbana, incluindo obras de saneamento e habitação.

Verifica-se, conforme apresentado na Tabela 1, que no estado de Minas Gerais houve uma expansão da produção de cana-de-açúcar de $188 \%$ no período de 2003 a 2011 . Para o estado de Sáo Paulo observou-se um aumento na produção de 55\%. Nos estados do 
Centro-Oeste o Mato Grosso do Sul apresentou um crescimento de 320\% e Goiás o índice foi de $253 \%$.

Tabela 1 - Produção de cana-de-açúcar nos principais estados produtores

\begin{tabular}{|c|c|c|c|c|c|c|c|c|c|}
\hline \multirow{2}{*}{ UF } & \multicolumn{9}{|c|}{ PRODUÇÁO DE CANA-DE-AÇÚCAR (em toneladas) } \\
\hline & $2003 / 04$ & $2004 / 05$ & 2005/06 & 2006/07 & $2007 / 08$ & 2008/09 & $2009 / 10$ & 2010/11 & $2011 / 12^{*}$ \\
\hline MG & 18.786 .524 & 20.945 .805 & 24.324 .538 & 29.153 .432 & 36.460 .100 & 44.208 .400 & 49.923 .400 & 56.013 .600 & 54.149 .100 \\
\hline SP & 206.513 .656 & 225.188 .102 & 241.222.574 & 265.379 .217 & 299.322 .300 & 342.910 .300 & 362.664 .700 & 361.723 .300 & 320.610 .300 \\
\hline Sudeste & 232.233 .700 & 256.455 .856 & 273.607 .042 & 300.867 .968 & 343.684 .300 & 395.094 .500 & 419.857 .700 & 423.799 .500 & 380.380 .100 \\
\hline$\% * *$ & $97,01 \%$ & $95,98 \%$ & $97,05 \%$ & $97,89 \%$ & $97,70 \%$ & $97,98 \%$ & $98,27 \%$ & $\mathbf{9 8 , 5 7 \%}$ & $98,52 \%$ \\
\hline MS & 8.805 .710 & 9.700 .048 & 9.037 .916 & 11.635 .093 & 14.662 .200 & 20.755 .000 & 23.297 .800 & 33.476 .700 & 37.002 .200 \\
\hline MT & 14.352 .164 & 15.078 .253 & 12.342 .929 & 13.059 .354 & 15.645 .000 & 16.109 .900 & 14.045 .600 & 13.661 .200 & 13.701 .500 \\
\hline GO & 13.041 .053 & 14.005 .856 & 14.568 .007 & 16.140 .042 & 21.055 .400 & 29.645 .200 & 40.092 .500 & 46.206 .800 & 45.998 .900 \\
\hline $\begin{array}{c}\text { C. } \\
\text { Oeste }\end{array}$ & 36.198.927 & 38.784 .157 & 35.948 .852 & 40.834 .489 & 51.362 .300 & 66.510 .100 & 77.435 .900 & 93.344 .700 & 96.702 .600 \\
\hline$\%^{* *}$ & $100 \%$ & $100 \%$ & $100 \%$ & $100 \%$ & $100 \%$ & $100 \%$ & $100 \%$ & $100 \%$ & $100 \%$ \\
\hline PR & 28.594 .395 & 23.736 .337 & 24.522 .773 & 32.118 .523 & 40.217 .600 & 44.200 .100 & 45.502 .800 & 43.321 .100 & 42.150 .400 \\
\hline Sul & 28.688.231 & 28.814.334 & 24.580 .749 & 32.210 .442 & 40.346 .200 & 44.320 .100 & 45.551 .300 & 43.403 .100 & 42.235 .400 \\
\hline$\% * *$ & $99,67 \%$ & $99,73 \%$ & $99,76 \%$ & $99,71 \%$ & $99,68 \%$ & $99,73 \%$ & $99,89 \%$ & $99,81 \%$ & $99,80 \%$ \\
\hline Brasil & 357.110 .883 & 381.447 .102 & 382.482 .002 & 428.816 .921 & 501.536 .300 & 571.809 .800 & 604.513 .700 & 632.905 .300 & 588.915 .000 \\
\hline$\% * * *$ & $81,23 \%$ & $82,23 \%$ & $85,24 \%$ & $85,70 \%$ & $85,21 \%$ & $87,06 \%$ & $88,59 \%$ & $87,60 \%$ & $87,21 \%$ \\
\hline
\end{tabular}

Fonte: Elaboração própria com dados do AGRIANUAL $(2011,2012)$.

Legenda: *Previsão em setembro/2011. **Representação da produçáo dos Estados em relação à produção das regiōes. ${ }^{* * *}$ Representação da produção dos Estados em relação à produção brasileira.

\section{METODOLOGIA}

A análise empírica dos fatores que influenciam o valor da terra será baseada em modelos de regressão de dados em painel. Uma vez que, ao referir-se aos determinantes do valor da terra, torna-se necessário considerar o comportamento das unidades individuais (municípios) ao longo do tempo. Este modelo, portanto, combina dados de séries de tempo e cross-section, o que permite um maior número de graus de liberdade e redução da colinearidade entre as variáveis explicativas. A especificação econométrica para esse modelo é apresentada na Equação 1.

$$
y_{i t}=\beta_{k}+\beta_{i t} X_{i t}+V_{i}
$$

onde a variável $y_{i t}$ é a variável dependente da unidade $i$ no ano $t$; os $\beta$ 's são os parâmetros a serem estimados; $X_{i t}$ representa as variáveis independentes da unidade $i$ no ano $t$, e $V_{i}$ corresponde a um termo de erro aleatório (WOODRIDGE, 2001). 


\subsection{Modelo analítico}

A especificação funcional proposta para o modelo completo está expressa na Equação (2) abaixo:

$$
\begin{aligned}
& v t_{i, t}=\beta_{1} \text { acsoja }_{i t}+\beta_{2} \text { prodsoja }_{i t}+\beta_{3} \text { vpsoja }_{i t}+\beta_{4} \text { accana }_{i t}+\beta_{5} \text { prodcana }_{i t}+ \\
& \beta_{6} \text { vpcana }_{i t}+\beta_{7} \text { acmilho }_{i t}+\beta_{8} \text { prodmilho }_{i t}+\beta_{9} \text { vpmilho }{ }_{i t}+\beta_{10} d+v_{i}
\end{aligned}
$$

em que $v t$ representa o valor da terra no município $i$ no ano $t$; acsoja a área cultivada de soja no município $i$ no ano $t$; prodsoja a produtividade de soja no município $i$ no ano t; vpsoja o valor da produção de soja no município $i$ no ano $t$, accana a área cultivada de cana no município $i$ no ano $t$, prodcana a produtividade da cana no município $i$ no ano $t$, vpcana o valor da produção de cana no município $i$ no ano $t$; acmilho a área cultivada de milho no município $i$ no ano $t$; prodmilho a produtividade de milho no município $i$ no ano $t$; vpmilho o valor da produção de milho no município $i$ no ano $t$, $d$ representa uma variável dummy que recebe o valor 1 se há usinas na cidade e zero se não há usinas na cidade analisada; e $v_{i}$ representa o termo de erro aleatório.

Uma vantagem desse modelo é o controle da heterogeneidade presente nas unidades, sendo capaz de isolar efeitos individuais, e assim controlar as diferenças existentes entre os estados (WOODRIDGE, 2001). E caso deste estudo, os municípios estudados podem ter atributos diversos que impactam no valor da terra, que não são possíveis de observar, tais como o grau de desenvolvimento, de ocupação agrícola, fatores culturais, entre outros. A omissão de tais fatores no modelo pode gerar resultados distorcidos (DUARTE; LAMOUNIER; TAKAMATSU, 2007), por isso é preciso utilizar técnicas que consigam reduzir esse problema.

\subsection{Fonte e tratamento de dados}

A metodologia do estudo contempla a utilização da base de dados extraída do Anuário da Agricultura Brasileira (Agrianual) para o período de 2003 a 2012, referente ao valor da terra agrícola de alta produtividade nos estados de Goiás e Minas Gerais. O Agrianual (2012) faz a classificação do valor da Terra em cinco categorias, sendo elas: Terra Agrícola de Alta Produtividade, Terra Agrícola de Baixa Produtividade, Pastagem Formada de Alto Suporte, Pastagem Formada de Baixo Suporte e Cerrado. Com o intuito de se obter uma delimitação de análise acerca das variáveis de estudo, optou-se em fazer uma coleta de dados restrita às terras de Alta Produtividade, incluindo os estados de Goiás e Minas Gerais. Segundo Lima (2010), o avanço da cultura da cana-de-açúcar sobre as áreas cultiváveis de grãos (principalmente soja e milho) nos estados de Goiás (nas mesorregióes do sul goiano, centro goiano, leste goiano e norte goiano) e Minas Gerais (mesorregião do Triângulo Mineiro e Alta Paranaíba) tem influenciado positivamente no valor da terra agrícola nestes estados. Portanto, a delimitação do estudo por terras de Alta Produtividade ocorre por priorizar a análise da dinâmica do valor da terra agrícola, principalmente pelo fato das usinas sucroalcooleiras estarem localizadas nestas regiōes, as mesmas onde estão localizadas as lavouras de milho e de soja, resultando em concorrência pelo uso do solo. 
Utilizaram-se ainda dados do Instituto Brasileiro de Geografia e Estatística (IBGE, 2014) para compilar os dados e montar as tabelas de área cultivada, produtividade e valor da produção para as culturas de soja, cana-de-açúcar e milho. O período de 2003 a 2012 se justifica porque a partir de 2003 contempla o início do Governo Lula que passa a estimular o setor sucroenergético com o objetivo de redução das emissóes de poluentes, cumprimento do Protocolo de Kyoto, assinatura do Plano Nacional de Agroenergia (PNA). Vários mecanismos de financiamento público foram utilizados por meio dos investimentos do Banco Nacional de Desenvolvimento Econômico e Social (BNDES), Moderfrota, dentre outros.

Para verificar a presença de usinas nos estados, foi consultado o material da relação de usinas na Associação das Indústrias Sucroenergéticas de Minas Gerais (SIAMIG, 2013) e no Sindicato da Indústria de Fabricação de Etanol do Estado de Goiás (SIFAEG, 2013). É importante ressaltar que os dados coletados são específicos para os municípios de Goiás e de Minas, cuja produção de cana-de-açúcar for superior que uma tonelada por hectare.

$\mathrm{Na}$ estimação do modelo proposto, utilizou-se o programa Stata 12.0. O Quadro 2 traz as informaçóes sobre as variáveis utilizadas, as quais resumem os fatores que são relevantes para explicar a dinâmica do valor da terra em Minas e Goiás.

Quadro 2 - Variáveis utilizadas, fontes de dados e descrição

\begin{tabular}{|c|c|l|}
\hline Variável & Fonte & \multicolumn{1}{c|}{ Descriçáo } \\
\hline$v t_{i, t}$ & Agrianual & Valor da terra agrícola de alta produtividade. \\
\hline acsoja $_{i t}$ & IBGE & Área cultivada de soja em hectare. \\
\hline prodsoja $_{i t}$ & IBGE & Produtividade de soja em kg/hectare. \\
\hline vpsoja $_{i t}$ & IBGE & Valor da produção de soja em hectare. \\
\hline accana $_{i t}$ & IBGE & Área cultivada de cana em hectare. \\
\hline prodcana $_{i t}$ & IBGE & Produtividade de cana em kg/hectare. \\
\hline vpcana $_{i t}$ & IBGE & Valor da produçáo de cana em hectare. \\
\hline acmilho $_{i t}$ & IBGE & Área cultivada de milho em hectare. \\
\hline prodmilho $_{i t}$ & IBGE & Produtividade de milho em kg/hectare. \\
\hline vpmilho $_{i t}$ & IBGE & Valor da produção de soja em hectare. \\
\hline$d$ & SIAMIG e SIFAEG & $\begin{array}{l}\text { Dummy que representa a presença ou não de usinas nos mu- } \\
\text { nicípios. }\end{array}$ \\
\hline
\end{tabular}

Fonte: Agrianual (2003-2012); IBGE (2003-2012); SIAMIG e SIFAEG (2013)

A adequação e a robustez dos resultados foram aferidas por diferentes estatísticas. Examinou-se a significância dos coeficientes para um modelo de efeitos fixos por meio do teste $\mathrm{F}$ de Chow sob a hipótese nula de que todos os interceptos diferenciais são iguais a zero. Testou-se também a presença de efeitos individuais com o teste do Multiplicador de Lagrange de Breusch e Pagan. Além disso, verificou se as diferenças nos coeficientes não são sistemáticas, comparando-se os modelos com efeitos fixos com modelos de efeitos aleatórios pelo teste de Hausman. 


\section{RESULTADOS E DISCUSSÃO}

\subsection{Estatísticas descritivas}

A Tabela 2 abaixo traz as estatísticas descritivas: média, desvio-padrão e coeficiente de variação $(\mathrm{CV})$ das variáveis que compóem a amostra final.

Tabela 2 - Estatísticas descritivas

\begin{tabular}{c|c|c|c|c}
\hline Variável & No obs. & Média & Desvio Padráo & CV \\
\hline$t_{i, t}$ & 1.390 & 8.390 & 3.634 & 0,433 \\
\hline acsoja $_{i t}$ & 1.390 & 16.204 & 34.689 & 2,141 \\
\hline prodsoja $_{i t}$ & 1.390 & 2.114 & 1.140 & 0,539 \\
\hline vpsoja $_{i t}$ & 1.390 & 26.103 & 60.499 & 2,318 \\
\hline accana $_{i t}$ & 1.390 & 6.166 & 8.006 & 1,298 \\
\hline prodcana $_{i t}$ & 1.390 & 70.013 & 28.645 & 0,409 \\
\hline vpcana $_{i t}$ & 1.390 & 20.695 & 31.629 & 1,528 \\
\hline acmilho $_{i t}$ & 1.390 & 6.633 & 15.757 & 2,375 \\
\hline prodmilho $_{i t}$ & 1.390 & 4.753 & 1.663 & 0,350 \\
\hline vpmilho $_{i t}$ & 1.390 & 37.685 & 77.752 & 2,063 \\
\hline$d$ & 1.390 & 0,27 & - & - \\
\hline
\end{tabular}

Fonte: Elaboração própria a partir de dados da pesquisa.

Observa-se que o valor médio da terra agrícola de alta produtividade foi de $\mathrm{R} \$ 8.390$, sendo que o maior valor encontrado foi de $\mathrm{R} \$ 21.000$, presente em 13 municípios mineiros (Ibiá, Indianópolis, Nova Ponte, Patos de Minas, entre outros) no ano de 2012 e o valor mínimo foi de R\$1.763, para o ano de 2003, também para cidades mineiras (Bocaiúva, Jaíba, Januária e Rio Pardo de Minas). O coeficiente de variação em torno de 43\% mostra uma alta dispersão dos dados em torno da média, indicando que o valor da terra difere bastante entre os municípios analisados.

A área cultivada teve a maior média para a cultura de soja (16.204 ha) com um coeficiente de variaçáo de 2,14, indicando uma elevada heterogeneidade dos dados na amostra. Em termos do valor da produção nota-se que, em média, nos estados de Goiás e Minas Gerais o valor produzido foi de: R \$ 26.103 na cultura de soja; R \$ 20.695 na produção de cana-de-açúcar e R 37.685 no cultivo de milho.

No que diz respeito a produtividade, observa-se que a produtividade média para a soja, entre os anos de 2003 a 2012, foi de $2.114 \mathrm{~kg} / \mathrm{ha}$ na amostra, com coeficiente de variação de 0,54; a produtividade média da cana-de-açúcar encontrada foi de $70.013 \mathrm{~kg} /$ ha com coeficiente de variação em cerca de $40 \%$; e a produtividade média do milho foi de $4.753 \mathrm{~kg} / \mathrm{ha}$ e desvio padrão de 1.663 . Chama a atenção a elevada produtividade média da cultura de cana-de-açúcar para as regiōes analisadas em comparação a produção de soja 
e milho. Por fim, observa-se que a amostra contém cerca de $27 \%$ dos municípios com a presença de usinas.

Neste estudo, a análise do impacto das variáveis do modelo sobre o valor da terra considera principalmente a renda da terra, utilizando como proxy para a renda o "valor da produção". Para os municípios em que a fronteira agrícola se evidencia com mais clareza, a cultura da soja e do milho tende a ser substituída pela cultura cana-de-açúcar, majorando o valor da terra nestas regióes.

Conforme Ferro e Castro (2013), a variável valor da terra defasado tem impacto significativo nas regiōes de fronteira agrícola, o que tem forte relação com a escolha de investimentos de agentes (até mesmo estrangeiros) nos anos recentes. Isso se justifica pelo elevado potencial de crescimento em termos de produção, instalação de agroindústrias e infraestrutura e, assim, tem resultado no processo de valorização da terra.

O resultado do teste de Breusch and Pagan $\left(\chi^{2}=551.63\right.$; Prob. $\left.>\chi^{2}=0.0000\right)$ indicou que efeitos aleatórios são preferíveis a dados empilhados. Do Teste de Chow observa-se que o modelo de efeitos fixos é melhor que o modelo de dados empilhados (estatística $F=7,29$; Prob. $>\mathrm{F}=0.0000)$. Já a estatística do Teste de Hausman $\left(\chi^{2}=51.36\right.$; Prob. $\left.>\chi^{2}=0.0000\right)$ indica que o modelo de efeitos fixos é preferível ao modelo de efeitos aleatórios. Portanto, a análise dos resultados obtidos pelos testes de Chow, Hausman e Breush-Pagan, indicou que a melhor opçáo foi o modelo de efeitos fixos. Ou seja, não podemos rejeitar a hipótese de que efeitos de heterogeneidades não observáveis nos municípios afetem o valor da terra. Em outras palavras, o modelo de efeitos fixos é preferível por considerar as particularidades presentes nos locais estudados.

A base de dados utilizada no estudo apresentou um total de 1.390 observaçóes, foram dez anos de informaçóes obtidas de 139 municípios. Conforme a Tabela 2 é possível verificar que o modelo completo com todas as variáveis propostas no estudo explica em torno de $45 \%$ da variaçáo do valor da terra (modelo A). Já para o outro caso (modelo B), o coeficiente de determinação foi de 0,66 , isso pode sinalizar que movimentos passados explicariam o comportamento dos próprios valores da terra agrícola, representando as expectativas dos agentes. 
Tabela 2 - Resultados obtidos para as estimativas

\begin{tabular}{|c|c|c|}
\hline \multirow{2}{*}{ Variável } & \multicolumn{2}{|c|}{ Modelo } \\
\hline & (A) & (B) \\
\hline acsoja & 0.0266 & -0.0003 \\
\hline prodsoja & $0.3000^{* *}$ & $0.6764^{* * *}$ \\
\hline vpsoja & 0.0065 & $-0.0085^{*}$ \\
\hline accana & 0.0176 & -0.0208 \\
\hline prodcana & $0.0111^{* * *}$ & 0.0030 \\
\hline vpcana & $0.0447^{* * *}$ & 0.0020 \\
\hline acmilho & 0.0201 & $0.0406^{* * *}$ \\
\hline prodmilho & $1.3279^{* * *}$ & $0.2876^{* * *}$ \\
\hline vpmilho & -0.0023 & -0.0006 \\
\hline$d$ & $1148.59^{* * *}$ & $720.51^{* * *}$ \\
\hline Iano_2004 & - & 1136. \\
\hline Iano_2005 & - & 104.37 \\
\hline Iano_2006 & - & -154.08 \\
\hline Iano_2007 & - & $709.61^{* *}$ \\
\hline Iano_2008 & - & $1812.65^{* * *}$ \\
\hline Iano_2009 & - & $2255.37^{* * *}$ \\
\hline Iano_2010 & - & $3529.49^{* * *}$ \\
\hline Iano_2011 & - & $5391.67^{* * *}$ \\
\hline Iano_2012 & - & $7819.84^{* * *}$ \\
\hline Constante & $-1319.39^{*}$ & $3014.22^{* * *}$ \\
\hline $\mathbf{R} 2$ & 0.4595 & 0.6600 \\
\hline $\mathbf{N}$ & 1390 & 1390 \\
\hline
\end{tabular}

Fonte: Dados da pesquisa.

Legenda: ${ }^{*} \mathrm{p}<0.05$; $^{* *} \mathrm{p}<0.01 ;{ }^{* * *} \mathrm{p}<0.001$

A segunda coluna da Tabela 2 mostra que em nenhuma das três culturas a variável que mede a área cultivada por hectare foi estatisticamente significativa. A opção de analisar o impacto na área cultivada sobre o valor da terra veio da sua representação da demanda por terras tanto de lavouras permanentes quanto temporárias. E, conforme mostra a literatura, o seu impacto sobre o valor da terra tende a depender da elasticidade da oferta deste fator, o que faz com que ela possa assumir tanto um sinal negativo quanto positivo. No entanto, o presente modelo náo conseguiu captar isso.

Em relação a produtividade, observa-se que as três variáveis (produtividade da soja, produtividade da cana e produtividade do milho) são positivas e estatisticamente significativas. $\mathrm{O}$ coeficiente de menor impacto sobre o valor da terra é o referente à variável cana $(0,011)$. Enquanto, para a soja e milho a produtividade impactou de forma substantiva, sendo que a produtividade da soja provoca uma variação de $30 \%$ e do milho de $132 \%$ no valor da terra. Isto condiz com a teoria de que, aumentando-se a produção por área, seria 
possível obter renda maior e, com isso, a valorização da terra. No mais, o aumento da produtividade agrícola também pode contribuir para o processo de valorização da terra ao atrair mais agricultores e indústrias para a região.

Ainda de acordo com o modelo A, em relação ao valor da produção, observa-se que somente a variável valor da produção da cana (vpcana) foi estatisticamente significativa (ao nível de 1\%) com impacto positivo, quando comparada às demais culturas analisadas. Assim, mantendo-se as demais variáveis constantes, um aumento de $1 \%$ do valor da produção da cana levaria a um aumento de aproximadamente $4,5 \%$ no valor da terra. Deste modo, espera-se que o valor produzido pela cana-de-açúcar seja um fator relevante para explicar a dinâmica do mercado de terras em certos momentos, dado que o valor da terra aqui analisado referem-se a duas de suas principais regióes produtoras.

Já para o modelo $\mathrm{B}$, que inclui variáveis binárias para os anos da amostra, apenas o valor da produção da soja foi estatisticamente significativo (ao nível de $10 \%$ ), contudo com o sinal contrário ao esperado. Tudo mais constante, espera-se que o aumento de $1 \%$ no valor da produção de soja leve a uma redução de $0,85 \%$ no valor da terra. Assim, sugere-se que a renda obtida com a terra (tendo como proxy neste estudo os valores da produção de soja, cana e milho), como encontrado na literatura, tem uma relação estreita com o valor deste fator de produção.

A variável que indica a presença de usinas foi estatisticamente significativa e positiva em ambos modelos, com o valor do coeficiente estimado muito elevado. Observa-se que, no modelo $\mathrm{B}$, as estimativas dos parâmetros para as variáveis em cada ano tornam-se mais significativas a partir de 2007, momento em que há a expansão da fronteira agrícola da cana-de-açúcar em substituição à soja e ao milho e, principalmente, os investimentos em usinas sucroalcooleiras. O Gráfico 1 corrobora tal fato, já que nele é possível observar que o número de usinas aumenta significativamente a partir de 2007. Cabe destacar que estes resultados não separam os dados de Minas Gerais e Goiás.

Gráfico 1 - Número de usinas por ano

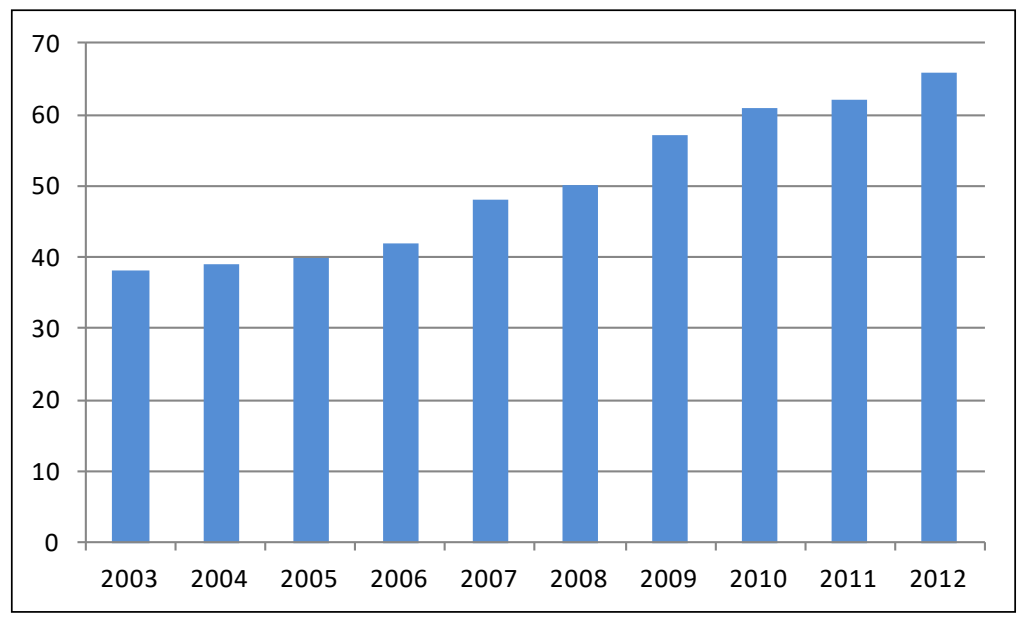

Fonte: Elaboração própria conforme dados coletados. 
O Brasil desde os anos 80 é o maior produtor e exportador de álcool e açúcar derivado da cana. A indústria sucroalcooleira encontra-se em elevado estágio de desenvolvimento tecnológico que, proporciona, associado a outros fatores de produçáo (disponibilidade e qualidade da terra; clima), uma posiçáo de destaque no mercado mundial. Ademais, a produção de cana-de-açúcar tem desempenhado papel de destaque no agronegócio e também na economia brasileira. Desde 2003, o governo retomou e priorizou a política de valorização do etanol enquanto uma alternativa à substituição dos combustíveis fósseis, com a maior visibilidade do açúcar no mercado de commodities e também a ampliaçáo da utilização de subprodutos da cana-de-açúcar e álcool, o que resultou na uma nova expansão da cultura da cana pelo território brasileiro.

Nessa perspectiva, dentro da maior região produtora de etanol e açúcar, a região centro-sul, que abrange o estado de Goiás e Minas Gerais (objetos de estudo deste trabalho) apresenta o menor custo de produção do mundo (GÓES, MARRA, SILVA, 2008). Assim, os fatores de produção que favorecem a cultura da cana-de-açúcar, o preço e a aceitação no mercado externo, impulsionam os produtores brasileiros em determinadas regióes a expansão de novas áreas de lavoras temporárias e permanentes, e também na substituição de culturas, antes tradicionais, como soja e milho, pela cultura da cana, implicando diretamente no valor da terra nessas regiōes.

\section{CONSIDERAÇÓES FINAIS}

Este estudo buscou entender quais as variáveis poderiam impactar o valor da terra nos estados de Minas Gerais e Goiás, em funçáo da expansão do cultivo da cana-de-açúcar no período de 2003 a 2012.

A produção de cana-de-açúcar há tempos tem um papel importante na economia brasileira. A partir de 2003 houve uma política de valorização do etanol, sendo considerada uma opção à substituição dos combustíveis fósseis, com a melhor visibilidade do açúcar no mercado de commodities, com a ampliação da utilização de subprodutos da cana-de-açúcar e álcool, houve nova motivaçáo para a uma expansão da cultura da cana pelo território brasileiro.

Observou-se que o modelo econométrico não capta o impacto da área cultivada (soja, milho e cana-de-açúcar) sobre o valor da terra, considerando a demanda por terra (lavouras temporárias e permanentes) que depende da elasticidade oferta do fator terra. $\mathrm{O}$ modelo mostra que a variável produtividade (da soja, milho e cana-de-açúcar) é positiva e estatisticamente significativa. Destaque para os coeficientes de produtividade da soja e do milho que causaram maior impacto sobre o valor da terra com cerca de $30 \%$ e $132 \%$, respectivamente, e em menor grau o coeficiente da cana-de-açúcar, $1,11 \%$ apenas. A teoria da renda da terra é confirmada, pois a elevação da produção por área e também da produtividade, obtém-se uma renda superior, o que resulta na valorização da terra, corroborando Barros (2009).

Portanto, a análise das variáveis demonstrou que existe uma correlação positiva entre o valor da terra e o aumento da produção de cana-de-açúcar nos dois estados em questão: Minas Gerais (mesorregiâo do Triângulo Mineiro e Alto Paranaíba) e Goiás. Isso corrobora 
a teoria sobre produtividade e valor da terra. A substituição de outras culturas como soja e milho pela cana-de-açúcar e o aumento do número de usinas sucroalcooleiras possibilitaram reflexo direto sobre o valor da terra nestas regióes.

Existem várias limitaçóes neste estudo, principalmente a dificuldade de obter de dados municipais específicos, como dados relacionados aos custos de produção, de transporte e variáveis sobre a evolução de infraestrutura. Sugere-se a realização de futuras pesquisas, quanto a evolução da disponibilidade de terras cultiváveis além daquelas de alta produtividade, e também dos dados dos estabelecimentos rurais negociados. Tais informaçóes resultariam em uma análise mais profunda sobre a oferta e demanda existente no mercado de terras, principalmente a partir de 2010 (especialmente na fronteira agrícola), quando foi restringida a aquisição de terras por estrangeiros no Brasil.

\section{REFERÊNCIAS}

AGRAFNP - Consultoria \& Comércio, AGRIANUAL 2003 a 2012. Anuário da agricultura brasileira. São Paulo; IFNP, 2003, 2004, 2005, 2006, 2007, 2008, 2009, 2010, 2011 e 2012. Impresso.

BARROS, G. S. C. O quebra-cabeça do preço da terra no Brasil. CEPEA, mimeo, 2009.

CASTRO, P. R. Organização fundiária e desenvolvimento: uma contribuição ao debate. Rio de Janeiro: Câmara dos deputados e Debates Econômicos e Sociais - CEDES, 1981, 129p.

CASTRO, A. C.; FONSECA, M. G. C. O potencial do agribusiness na fronteira. Revista de Economia Política, v.14. n.1(53), jan-mar, 1994. Disponível em: http://www.rep.org. br/pdf/53-6.pdf. Acesso em: 19 jan. 2014.

COMPANHIA NACIONAL DE ABASTECIMENTO (CONAB). Acompanhamento da safra brasileira de cana-de-açúcar. Brasília: CONAB, Safra 2013/14, Segundo levantamento 08/16, v.3, n.2, 2014. Disponível em: http://www.conab.gov.br. Acesso em: 18 Ago. 2014.

DELGADO, G. C.; FERNANDES FILHO, J. F. Determinantes da queda recente do preço da terra no Brasil. Revista Ensaios. IE/UFU, Uberlândia, v.12, p.13, 1998.

DELGADO, G. C. A questão agrária no Brasil, 1950-2003. In: JACCOUD, L. (Org.) Questão Social e Políticas Sociais no Brasil Contemporâneo. Brasília, IPEA, p.5190, 2005. Disponível em: https://www.ipea.gov.br/agencia/images/stories/PDFs/livros/ Cap_2-10.pdf. Acesso em: 20 jan. 2014.

DIAS, G. L. S.; VIEIRA, C. A.; AMARAL, C. M. Comportamento do mercado de terras no Brasil. Red de Desarrollo Agropecuario. Unidad de Desarrollo Agrícola. División 
de Desarrollo Productivo y Empresarial. CEPAL, 2001. Disponível em: http://www. eclac.cl/publicaciones/xml/8/6838/LCL1484P.pdf. Acesso em: 20 jan. 2014.

DUARTE, P. C.; LAMOUNIER, W.M.; TAKAMATSU, R.T. Modelos econométricos para dados em painel: aspectos teóricos e exemplos de aplicação à pesquisa em contabilidade e finanças. In: CONGRESSO USP DE CONTROLADORIA E CONTABILIDADE, Anais... São Paulo, p. 1-15, 2007.

EGLER, C. A. G. Preço da terra, taxa de juro e acumulação financeira no Brasil. Revista de Economia Política. São Paulo, v.5, n.1, p.112-135, jan./mar, 1985. Disponível em: http://www.rep.org.br/pdf/17-6.pdf. Acesso em: 20 jan. 2014.

FEDERAÇÃO DA AGRICULTURA DO ESTADO DE GOIÁS (FAEG), 2009.

Disponível em: http://www.sistemafaeg.com.br/busca-no-site. Acesso em: 23 jun. 2013.

FERREIRA, N.C.; MIZIARA, F.; RIBEIRO, N. V. Preço da terra em Goiás: pressupostos e modelos. Boletim Goiano de Geografia. Goiânia, v.27, n.1, 2007. Instituto de Estudos Sócio-Ambientais-IESA/UFG. Disponível em:<www.revistas.ufg.br/index.php/bgg/ article/download/3440/3304>. Acesso em: 20 jan. 2014.

FERRO, A. B.; CASTRO, E. R. Determinantes dos preços de terras no Brasil: uma análise de região de fronteira agrícola e áreas tradicionais. Revista de Economia e Sociologia Rural. Brasília, v.51, n.3, jul./set., 2013. Disponível em: http://www.scielo.br/ scielo.php?pid=S0103-20032013000300010\&script=sci_arttext. Acesso em: 4 jan. 2014.

GASQUES, J. G.; BASTOS, E. T.; VALDES, C. Preços da terra no Brasil. In: XLVI CONGRESSO DE SOCIEDADE BRASILEIRA DE ECONOMIA, DE ADMINISTRAÇÃO E DE SOCIOLOGIA RURAL, 46, 2008. Anais eletrônicos... Rio Branco: SOBER, 2008. Disponível em: http://ageconsearch.umn.edu/ bitstream/106106/2/587.pdf. Acesso em: 18 jan. 2014.

GÓES, T.; MARRA, R.; SILVA, G. S. Setor sucroalcooleiro no Brasil: Situação atual e perspectivas. Revista de Política Agrícola, ano XVII, n.2, abr./mai./jun. 2008.

INTITUTO BRASILEIRO DE GEOGRAFIA E ESTATÍSTICA (IBGE). Produçáo Agrícola Municipal - PAM, 2002-2013. Disponível em: http://www.ibge.gov.br/home/. Acesso em: 4 Abr. 2014.

LIMA, D. A. L. L. Estrutura e Expansão da Agroindústria Canavieira no Sudoeste Goiano: impactos no uso do solo e na estrutura fundiária a partir de 1990. Campinas-SP: [s/n], 2010. (Tese de Doutorado) - Universidade Estadual de Campinas, Instituto de Economia, 2010.

MALASSISE, R. L. S.; PARRÉ, J. L.; FRAGA, G. J . O Comportamento do Preço da Terra Agrícola: um modelo de painel de dados espaciais. Rev. Econ. Sociol. 
Rural, Brasília, v.53, n.4, out./dez. 2015. Disponível em: http://www.scielo.br/scielo. php?script=sci_arttext\&pid=S0103-20032015000400645. Acesso em: 23 jan. 2018.

MALTHUS, T.; R. Princípios de Economia Política e Consideraçóes Sobre sua Aplicação Prática. São Paulo: Nova Cultural, 1996.

MARX, K. O Capital: crítica da economia política. Rio de Janeiro: Civilização Brasileira, 2008.

OTTO, I. M. C.; NEVES, M. F.; PINTO, M. J. A. Cadeia produtiva sucroenergética FIEG. Goiânia, 2012.

PINHEIRO, F. A. A renda e o preço da terra: uma contribuiçáo à análise da questáo agrária brasileira. Piracicaba, 1980, 277p. Tese de Livre Docência - Escola Superior de Agricultura "Luiz de Queiroz", Universidade de São Paulo.

PINHEIRO, F. A; REYDON, B. P. O preço da terra e a questão agrária: algumas evidências empíricas relevantes. Revista de Economia Rural, v. 19, n.1, p.5-15, jan./ mar. 1981 .

PLATA, L. E. A. Mercados de terras no Brasil: gênese, determinação de seus preços e políticas. Campinas, SP: IE/UNICAMP. (Tese de doutorado), 2001.

PLATA, L. E. A. Dinâmica do preço da terra rural no Brasil: uma análise de co-integração. (Orgs.) REYDON, B. P.; CORNÉLIO, F. N. M. V. Mercados de terras no Brasil: estrutura e dinâmica. Brasília: NEAD, 2006. 444p. Disponível em: www.nead.gov.br/ portal/nead/nead-debate/download_orig_file?...id... Acesso em: 15 nov. 2013

RANGEL. I. M. Questão agrária e agricultura. Rio de Janeiro, Civilização Brasileira, 1979 (Encontros da civilização Brasileira, 7).

RAHAL, C. S. A evolução dos preços da terra no estado de São Paulo: Análise de seus determinantes. Piracicaba, SP: ESALQ/USP (Dissertação de mestrado), 2003.

REYDON, B. P. Mercados de terras agrícolas e determinantes de seus preços no Brasil: um estudo de caso. Campinas, IE/UNICAMP. (Tese de doutorado), 1992. Disponível em: http://www.bibliotecadigital.unicamp.br/document/?code=000045371\&opt=1. Acesso em: 20 jan. 2014.

REZENDE, G. C. Ocupação agrícola e estrutura agrária no cerrado: o papel do preço da terra, dos recursos naturais e da tecnologia. In: CONGRESSO DE SOCIEDADE BRASILEIRA DE ECONOMIA, DE ADMINISTRAÇÃO E DE SOCIOLOGIA RURAL. Anais eletrônicos Passo Fundo-RS: SOBER, 2002.

RICARDO, D. Princípios de Economia Política e Tributaçáo. $3^{a}$ ed., São Paulo: Nova Cultural, 1988. 
SIAMIG. Associação das Indústrias Sucroenergéticas de Minas Gerais, 2013.

SIFAEG. Sindicato da Indústria de Fabricação de Etanol do Estado de Goiás.

Disponível em: http://www.sifaeg.com.br/mapadasusinas/. Acesso em: 20 nov. 2013.

SILVA, A. A; MIZIARA, F. Avanço do setor sucroalcooleiro e expansão da fronteira agrícola em Goiás. Pesquisa Agropecuária Tropical, Goiânia, v.41, n.3, p.399-

407, jul/set. 2011. Disponível em: http://www.revistas.ufg.br/index.php/pat/article/ viewFile/11054/9648. Acesso em: 19 jan. 2014.

SAYAD, J. Preço da terra e mercados financeiros. Pesquisa e Planejamento Econômico, Rio de Janeiro, v. 7, n.3, p. 623-662, dez. 1977. Disponível em: http://ppe.ipea.gov.br/ index.php/ppe/article/viewFile/587/529. Acesso em: 20 jan. 2014

UNICA, Uniáo da indústria de Cana-de-açúcar (2011 e 2013). Disponível em: www. unica.com.br. Acesso em: 15 jun. 2014.

WOODRIDGE, J. M. Econometric Analysis of Cross Section and Panel Data.

Cambridge: MIT Press, 2001. 